\title{
sciendo
}

$10.2478 / \mathrm{msd}-2019-0010$

\section{OPPORTUNITIES, CHALLENGES AND ETHICAL CONSIDERATIONS AS INSIDER-RESEARCHER FOR A COMMUNITY-BASED RESEARCH IN REDRESSING LIVELIHOOD SUSTAINABILITY ISSUES}

\author{
Emerson Abraham, JACKSON \\ Doctoral Research Scholar, Centre of West African Studies, University of Birmingham and Senior Research Economist, Bank of \\ Sierra Leone
}

\begin{abstract}
The thought about taking an ethical view-point to this research has emanated from the researcher's journey in preparing for a baseline survey of residents in Goderich using the Community-Based Research Participation (CBRP) approach to investigating concerns pertaining to sustainable livelihood needs. In as much as the overarching focus of the research is aimed at meaningful contribution to the body of knowledge, it was worth the effort in journeying through this phronetic / ethical exploration, which is not so common in research engagements carried out in developing countries like Sierra Leone. The role of the researcher as an insider was thoroughly explored, with the view of openness raised as the preferred option as a way of eliciting unbiased outcomes from participants and also, removing power domination, most often witnessed in researcher-participants relation with most research undertakings.
\end{abstract}

KEYWORDS: Ethics; CBRP; Insider-researcher; Livelihood Sustainability; Sierra Leone

\section{INTRODUCTION}

The process involved in undertaking a research can be an exploratory venture and it also brings with it some critical questions to answer, both in the case as an insider or an outsider researcher who is new to the research community under study. Phronetic ethical practice is hard to come by with research undertakings (be it CBRP or other approaches) in developing countries, such as that experienced by the author, both as a research scholar and a practicing researcher.

All across the globe, there is concerted effort made in raising awareness about discourses relating to environmental and livelihood sustainability (Jackson, 2015a, Munro, 2009 and Cline-Cole, 1984). Such discourses are also typical of Sierra Leone, a small coastal nation found in the West African Subregion. On account of the brutal crisis which started to pervade the country in the late 1980 s, there was a marked / noticeable evidence of historical degradation experienced in the natural environment, particularly its forest reserve (Jackson, 2015b and 2015c). Despite the natural preservation of forests, there is also intrinsic value it places on daily livelihood for residents, who also have diversified their state of living through natural forest assets (e.g., wood fetching, charcoal extraction, agro-forestry, etc.).

With the mounting state of degradation experienced in Goderich, poor and vulnerable residents seem to have no option, but to seek the most accessible means of adaptation in order to meet family / personal livelihood needs. Such alternative means of livelihoods incorporate activities like sand mining, unprecedented state of land grabbing and many more, which in effect, is worrying for environmental sustainability.
The aforementioned issues have heightened concerns by people with attention focused in protecting their historic heritage, for example, the restoration of land degraded terrain and also concerns around increase in sea level on account of excessive sand mining. Weaknesses in power dynamics and also acute state of poverty for most people meant that they could not raise their concerns aloud, rather than gossiping within small circle of (disgruntled) communities. On the other hand, some people have being bold enough to air their concerns - this article is about raising awareness about ethical concerns and the need for community-based-participation amongst people. Various research undertakings have attested to improved outcomes and participation where communitybased-participation is vibrant (Forsythe et al, 2016 and Strike et al, 2017).

\section{AIM AND OBJECTIVES OF THE STUDY}

This research article is aimed at addressing the concept of Community-Based Research Participation (CBRP) as perceived from a sustainable livelihood perspective, where historical trend in levels of change in natural habitation is forcing residents, particularly in rural communities like Goderich to adapt to the most easy means of livelihoods on account of their exposed vulnerabilities. On this note, the perceived objectives are listed below:

- Explain the concept of CBRP, its opportunities and challenges in the perspectives of sustainable livelihood dynamics in Goderich.

- Address concerns around ethical issues, with respect to an insider perspectives and its influence in effecting (positive) desired changes. 
- Provide considered recommendations for the benefit of effecting dialogue for community collaboration in Goderich.

\section{THE COMMUNITY BASED ENVIRONMENT}

The community in focus for which this article is geared towards is Goderich; a coastal community located along the sea-shore of Freetown in Sierra Leone. It is historically well known for its varied livelihood activities, for which fishing was once the most dominant, but also remain popular for its natural location which is an attraction for eco-tourism. The environment used to be densely forested and this has made it possible for community life to be buoyant through rich cultural and social activities, for which hunting is a common example (Jackson, 2015c). In addition to this, forest plays vital role for livelihood sustenance, through which most residents access forest activities like firewoods, charcoal and also hunting for bio-diversified range of creatures (ClineCole, 1984).

This is a unique characteristics which makes it essential to address ethical concerns and for which, the researcher is considered as an insider-researcher, that is, being part and parcel of the community. Community-based participatory research of this type can be traced as far back as in the 1940s as addressed by Kurt Lewin (1946) who was a Social Psychologist; this requires active involvement in a research exercise by those affected by problems being studied through fact finding, action and reflection. Community-Based Research Participation (CBRP) is highly used in exploring issues in health related area, but its applicability can also be applied in other areas of community-based study as in the case with the author's scholarly work (sustainable livelihood Issues).

This type of approach to research in exploring community involvement is quite good in capturing common concerns by people, particularly in a situation involving an insiderresearcher's role in probing common problems like the current state of environmental degradation and a possible heightened risks to future environmental disaster in the Goderich community. This can be viewed as a form of political research approach which is geared towards raising awareness about (deplorable) concerns in communities, but given the nature of the intending research work [incorporating both structured survey and group interviews], its use is good for influencing policy decisions and also adding value to on-going ontological quest for the nature of being and knowledge acquisition (Jackson, 2016a and 2016c).

\subsection{Challenges}

Environmental concerns is a common challenge on how people perceive the impact of their actions to the environment; as currently seen in the situation with Goderich, environmental landscape is changing, mainly as a result of people's quest for sustained livelihoods. In a community such as Goderich where high percentage of the participating population is semi-literate, the approach to engaging with people on CBRP should be treated with care, and sensitively in order to avoid problems associated with risk of interfering on the well-being of those perceiving themselves as being marginalised. As explained by Tervalon and Murray-Garcia
(1998), CBRP also embodied deep form of commitment to 'cultural humility', where people can be made to feel the need to address aspects of their cultural heritage in the community. Goderich is a resource-rich and diverse populated community; this is manifested through diverse activities of people, for example, religious engagement, cultural activities and also different forms of livelihoods engagement (fishing and forest activities) that characterises its importance in the country as a whole.

\subsection{Opportunities}

Despite the aforementioned challenges, the use of community-based participatory research approach (will) provide the means for improvement in way of doing things, particularly through study of events happening in communities, such as Goderich. Categorised into four main types (Participant Observer, Rapid Rural Appraisal [RRA], Participatory Rural Appraisal [PRA] and Participatory Action Research [PAR]), CBRP create opportunity for community concerns like issue of threats to livelihoods to be unearthed in a way that enable people to raise concerns, which also result in positive change to societal way of life (Rennie and Singh, 1995). In this type of study, field work is considered as an essential component of understanding concerns of communities, while at the same time ensuring issues of concerns are dealt with in the best possible way to improve outcome(s) and community cohesiveness. In the case with sustainable livelihood research undertakings, CBRP is viewed as both an outcome and as well as a form of community action project which may also raise awareness on the part of central government about future impact of threats to environmental sustainability, on account of adaptability techniques people in Goderich are using to sustain lives.

\section{THE RESEARCH SETTING AND RATIONALE}

This is based on field participation (incorporating baseline surveys and interviews), spanning over three months, due to the nature of it being a full investigation into livelihood dynamics. In other words, the researcher has identified samples from population which will be studied in order to address livelihood patterns, vulnerability and adaptability to shocks / hideous conditions. The purpose of this venture is firstly, to address personal interest in the award of a higher qualification in Sustainable Livelihood and Development, while the secondary is to ensure that the researcher's interests on evolving changes over the time spent are captured with the ultimate goal of proposing policy recommendations that will ultimately impact (positively) on lives in the wider community. Community concerns looming in the area of environmental degradation is intuitively worrying and also raises ethical question around future cohesiveness of people / groups in the community.

\section{POWER AND CONFIDENTIALITY AS AN ETHICAL ISSUES}

Power relation / dominance is a critical aspect for CBRP and as addressed in research published by Jackson (2016b and 2018), there is a need for ethical prudence (phonetic values) to be manifested by the researcher, especially in situations where insider approach is to be the focus. The fact that the 
researcher is coming as an insider, poses some level of compromise, which means value judgement might easily be skewed to that which is biased towards the majority's perceived thoughts on environmental concerns.

The need to explore scope for sustained livelihood, particularly in an area where the effect of changes (increased population and also reduced scope for traditional means of livelihoods like fishing and forest-farming on account of over-exploitation and government legislations) has made it very difficult to access assets (sea / forest as natural assets) that were once easily accessible, is sure to raise some levels of ethical concerns. For an insider-researcher, the best way forward is to remain indifferent about concerns raised, while the underlying objective is to seek avenues in compromising differences on human understanding of environmental degradation.

The ultimate means of survival is to seek ways and means of accessing opportunities for sustained survival by applying mixed methods approach (Jackson, 2018b). The situation as it is currently (with high levels of environmental degradation) in Goderich, manifest some form of divide in opinions on the level of adaptive survival techniques people (e.g., sand mining, etc) are using to access assets for their survival. As a concerned indigene and also insider-researcher of the community, it is easy for personal judgement to take precedence. Critical hermeneutics on the other hand can also influence the mind to address objectivism and on which the philosophical dictum of intellectual virtue can prevail.

Therefore, consent is very important for the success of engagement as an insider-researcher on the type of sustainable livelihood project the researcher is undertaking. Highest level of trust and confidentiality is needed from the onset to affirm people's confidence about the need for CBRP study, where (negative) emotions are likely to be vented about concerns for the environment and also, in the area of (lagged) policy actions needed to raise people's trust in rebuilding collapsed environment and communities.

\section{CONCLUSION AND RECOMMENDATION}

In the journey of engaging in CBRP, such as that which is focused on actions aimed at enhancing sustainable environmental conditions, the researcher, whether as an insider or outsider, must ensure confidentiality about people's identity is concealed - a testification of a similar qualitative enquiry on "Contested terrain of sustainable development paradigm in Sierra Leone also revealed the researcher's efforts in managing anonymity (Jackson, 2018a). The researcher's emotion, more so when he/she is perceived as an insider-researcher, must remain neutral. In so doing, it will surely help the process of CBRP to be successfully achieved, such that concerns pertaining to environmental degradation and future sustainability will be brought to the fore, while community members are more likely to be open minded in addressing issues of concern.

The management of mixed emotions is very important, especially when the insider approach is used, but with all its ethical transparency, the non-biased state of the researcher's engagement is the most important, even when personal opinion may be the dictating force. The researcher, from the onset, is aware about biased state of mind, particularly knowing very well the (high) risk involved in preserving the reputation of a prestigious university, which might face the endearing pain of disrepute when ethical procedures, for example, confidentiality and also, participants' anonymity are breached.

On the way forward to maintaining high level of integrity in future dealing associated with CBRP, it is highly recommended that strict ethical code of practices are used, where prolonged awaited time of ethics committee's approval is considered necessary to maintaining ethical standards. In developing countries such as Sierra Leone, where this is not an enforced practice amongst higher educational and other research-focused institutions, the establishment of ethical standard is worthwhile to increase research profile and confidence in the research profession.

In order to maintain high standard in outcomes from CBRP ventures, researchers must ensure documents like "structured questionnaires and interview handouts" are simplified to the level needed for the most common consented adult in understanding the purpose of the research and also, its desired impacts. This approach will minimise power control expected from the interviewer / researcher and most likely serve as means for the facilitation of high level participation from participants in the identified research communities.

\section{REFERENCES}

1. Cline-Cole, R.A. (1984). 'Towards an Understanding of Man Firewood Relations in Freetown (Sierra Leone). Geoforum. Vol. 15(4): 583-594.

2. Jackson, E.A. (2015a). Deforestation on the Freetown Peninsula - A Case of Livelihood and Biodiversity Loss in the Goderich Community. International Journal of Research in Agriculture and Forestry, Vol. 2(7): pp. 2134.

3. Jackson, E.A. (2015b). Negotiating New Dimensions for Forests Conservation in Sierra Leone. Journal of Applied Thought, Vol. 4(2): pp. 86-102.

4. Jackson, E.A. (2015c). FLEGT Mandate: Its applicability and effectiveness in Sierra Leone. Journal of Applied Thought, Vol. 4(3): pp. 84-100.

5. Jackson, E.A. (2016a). Phronesis and Hermeneutics: The Construct of Social / Economic Phenomenon and their Interpretation for a Sustainable Society. Journal of Economic Insights Trends and Challenges, Vol. 8(2): pp. 18 .

6. Jackson (2016b). Phronesis and the Epistemological journey through research undertakings involving human participants in the context of Sierra Leone. Filosofia Theoretica: Journal of African Philosophy, Culture and Religions, Vol. 5(2): pp. 37-53. DOI: 10.4314/ft.v5i2.3.

7. Jackson, E.A. (2016c). Ontological and Epistemological Discourse(s) on Sustainable Development: Perspective on Sierra Leone in the Aftermath of a Decade of Civil Unrest. Management of Sustainable Development Journal, Cool. 8(1): pp. 35 - 43. DOI: 10.1515/msd-20160005 .

8. Jackson, E.A. (2018). Research Methodology in the Social Sciences: Perspectives on Sierra Leone. United Kingdom: Lulu Publisher. 
9. Jackson, E.A. (2018a). Contested Terrain of Sustainable Development Paradigm in Sierra Leone. Management of Sustainable Development Journal, Vol. 10(1): pp. 5-11. DOI: $10.2478 / \mathrm{msd}-2018-0001$.

10. Jackson. E.A. (2018b). Challenges of Research Methodology in Practice and the Epistemic Notion of Mixed methods in the Academia. International Journal of Interdisciplinary Research Methods, Vol. 5(1): pp. 19 31 .

19. Lewin K (1946). Action research and minority problems. J Soc Issues., Vol. 2: pp. 3446.

11. Munro, P.G. (2009), Deforestation: constructing problems and solutions on Sierra Leone's Freetown Peninsula (Online). Vol. 16, pp. 104 - 123. [Accessed: $20^{\text {th }} \quad$ June 20157 . Available at: $<$ http://jpe.library.arizona.edu/volume_16/Munro.pdf $>$.

12. Rennie, K.J., and Singh, N.C. (1995). Participatory Research for Sustainable Livelihoods A Guide for Field Projects. International Institute for Sustainable Development. Manitoba, Canada.

13. Strike, C., Guta, A., de Prinse, K., Switzer, S. and Chan Carusone, S. (2017). Opportunities, challenges and ethical issues associated with conducting communitybased participatory research in a hospital setting. Journal of Research Ethics, Vol. 12(3): pp. 149-157.

14. Tervalon M, Murray-Garcia J. (1998). Cultural humility vs. cultural competence: a critical distinction in defining physician training outcomes in medical education. $\mathbf{J}$ Health Care Poor Underserved. Vol. 9: pp. 117-125 